\title{
BIMBINGAN BELAJAR DUTASIA DI TAMAN BACAAN, BENCONGAN
}

\author{
Ariani Tandi Padang1, Budi Wibawanta ${ }^{2}$ \\ ${ }^{1}$ Universitas Pelita Harapan \\ ${ }^{2}$ Universitas Pelita Harapan
}

ariani.padang@uph.edu, budi.wibawanta@uph.edu

\begin{abstract}
Abstrak
Pendidikan merupakan salah satu faktor utama yang turut ambil bagian dalam pembangunan bangsa sehingga, setiap lapisan masyarakat berhak menerima pendidikan yang layak. Akan tetapi, belum semua lapisan masyarakat memeroleh kesempatan belajar yang maksimal karena terbentur dengan terbatasnya finansial dan kemampuan keluarga dalam memberikan bimbingan belajar. Kondisi ini terlihat pada daerah Bencongan yang mayoritas orangtua bekerja sebagai buruh harian, tukang ojek, atau pramuniaga serta penghasilan dibawa UMR provensi Banten. Berdasarkan hal tersebut, UPH Teachers College bekerja sama dengan yayasan Dutasia untuk menyediakan lingkungan belajar yang inovatif, kondusif, dan gratis bagi masyarakat Bencongan. Metode pelaksanaan PkM adalah mahasiswa UPH akan menjadi tutor bagi anak-anak Bencongan setiap hari SeninKamis pada pukul 19.30 - 21.00. Adapun tujuan pelaksanaannya adalah meningkatkan kemampuan holistis anak-anak Bencongan, serta mahasiswa UPH sebagai tutor dapat mengembangkan keterampilan mengajar yang inovatif dan pengembangan kepribadian sebagai guru Kristen yang dewasa. Hasil dari kegiatan ini adalah Kegiatan ini adalah 1) 100\% tuttee memiliki kemampuan akademik (pengetahuan dan keterampilan) yang telah meningkat; 2) 96\% tutor mampu mengembangkan diri sebagai anggota komunitas yang signifikan; 3) 96\% mahasiswa telah membangun karakter dan kemandirian mahasiswa sebagai seorang Kristen yang dewasa; 4) 85\% mahasiswa menggunakan metode mengajar yang inovatif dalam kesempatan mengajar secara langsung dengan para siswa.
\end{abstract}

Kata Kunci : pendidikan, bimbingan belajar, tutor, holistis

\section{PENDAHULUAN}

Pendidikan merupakan salah satu faktor
utama yang turut ambil bagian dalam
pembangunan bangsa. Hal tersebut juga tertulis
pada Undang-undang RI nomor 20 tahun 2003
Bab 1 pasal pertama menguraikan dengan jelas
bahwa "Pendidikan adalah usaha sadar terencana
untuk mewujudkan suasana belajar dan proses
pembelajaran agar peserta didik secara aktif
mengembangkan potensi dirinya untuk memiliki
kekuatan spiritual keagamaan, pengendalian diri,
kepribadian, kecerdasan, ahlak mulia, serta
keterampilan yang diperlukan dirinya,
masyarakat, bangsa dan negara". Pendidikan

diperlukan bukan hanya sekedar bertahan hidup, tetapi juga memberikan perubahan pola pikir yang dapat membuat kita memandang hidup lebih bermakna berdasarkan perintah agung untuk mengasihi Tuhan dan sesama (Van Brummelen, 2006). Dengan demikian, maka tidak berlebihan jika kita juga menyebutkan pendidikan merupakan investasi dengan keuntungan deviden tanpa batas akhir.

Pendidikan seharusnya menjadi hak bagi setiap anak tanpa kendala. Sayangnya, belum semua anak memeroleh pendidikan kualitas yang sama karena terbatas pada finansial. Demikian juga yang dialami oleh masyarakat Bencongan. 
Keterbatasan biaya membuat mereka memberikan layanan pendidikan kepada anak-anak seadanya.

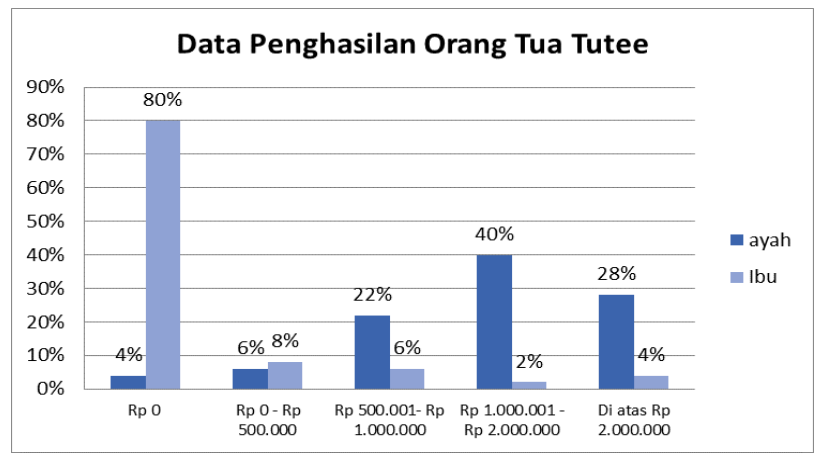

Gambar 1. Data Penghasilan Orang Tua Tutee desa Bencongan Sumber : hasil pengolahan data, 2019

Data yang diperoleh menunjukkan bahwa $72 \%$ penghasilan ayah dibawah Rp 2.000 .000 dan hampir $80 \%$ ibu tidak memiliki penghasilan. Sementara untuk upah minimum provinsi (UMP) banten untuk tahun 2019 sebesar Rp 2.267.965. Hal ini berarti pendapatan rata-rata keluarga bencongan di bawah UMP. Kondisi ini membuat orang tua harus mencari pekerjaan tambahan untuk memenuhi kebutuhan keluarga sehingga waktu mereka untuk mendampingi anak-anak belajar di rumah pun semakin terbatas.

Selain kondisi finansial, faktor Pendidikan orang tua juga membuat orang tua merasa belum mampu mendampingi anak-anak belajar di rumah. Hal tersebut juga terlihat dari hasil survei yang menunjukkan bahwa

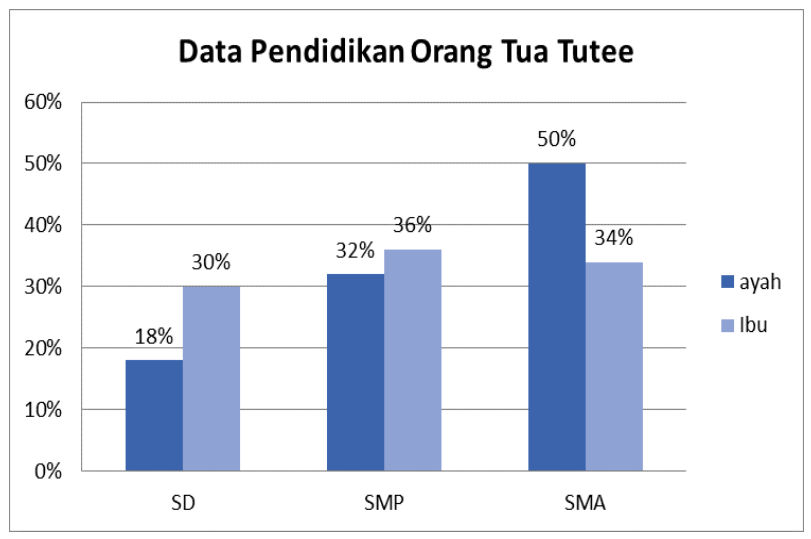

Gambar 2. Data Pendidikan Orang tua Tutee desa Bencongan Sumber: Hasil Pengolahan Data, 2019

pendidikan orang tua anak maksimal SMA, yaitu $50 \%$ ayah dan $34 \%$ ibu, sisanya mengenyam bangku pindidikan hanya sampai SD dan SMP. Dengan pengalaman Pendidikan yang orang tua miliki, maka mereka merasa membutuhkan bantuan dari pihak lain untuk membantu anak-anak bencongan lebih maksimal belajar.

Berdasarkan uraian di atas, dapat dilihat bagaimana keterbatasan orang tua, baik secara finansial maupun akademik dalam memberikan pendampingan pendidikan kepada anak-anak di Bencongan. Melihat hal tersebut, kami Program Studi Pendidikan IPS, Fakultas Ilmu Pendidikan UPH terpanggil untuk turut berperan serta dalam membantu dunia pendidikan di Indonesia secara lingkup kecil di dalam pelaksanaan bimbingan belajar di Bencongan Indah, Kelapa Dua, Tangerang, Banten. Melalui kegiatan ini dosen beserta mahasiswa FIP-Teachers College UPH mendapat kesempatan untuk melakukan proses kegiatan mengajar di lingkungan masyarakat.

Adapun tujuan dari pelaksanaan kegiatan ini adalah meningkatkan kemampuan holistis anakanak Bencongan. Selain itu, Mahasiswa UPH yang berperan sebagai tutor juga dapat mengembangkan keterampilan mengajar yang inovatif dan pengembangan kepribadiannya sebagai guru Kristen yang dewasa.

Dalam pelaksanaan PkM ini, UPH Teaachers College bekerja sama dengan Yayasan Dutasia untuk menyiapkan lingkungan belajar yang kondusif. Selain mempersiapkan tutor untuk mengajar anak-anak Bencongan, UPH juga turut andil dalam memberikan bantuan berupa perlengkapan belajar dan mengajar, seperti alat tulis kantor, permainan yang edukatif, dan meja belajar.

\section{METODE}

Kegiatan yang dilakukan ini bekerja sama dengan Yayasan Dutasia (Peduli Antar Manusia) sebagai salah satu organisasi pembelajaran yang memiliki tujuan awal untuk membantu biaya sekolah anak-anak yang kurang mampu telah menjalin kerjasama dengan FIP-Teachers College UPH sejak tahun 2007 dalam kegiatan pembelajaran di beberapa lokasi. Salah satu dari lokasi atau pos yang dimiliki adalah Pos Taman Bacaan,

$$
\text { Pendidikan }
$$


Bencongan Indah, Kelapa Dua, Tangerang, Banten. Kegiatan bimbingan belajar dilakukan di rumah warga.

Proses belajar mengajar di Taman Bacaan, dilaksanakan setiap hari Senin-Kamis dalam durasi waktu 19.00-21.00 WIB. Setiap harinya akan ada 17-20 tutor yang akan ikut mengajar. Tutor akan berkumpul dibawah Food Jungtion UPH sebelum jam 19.00 dan akan berangkat bersama menuju Taman Bacaan dengan berjalan kaki. Waktu yang dibutuhkan dalam perjalan \pm 20 - 25 menit. Tutee yang hadir di Taman Bacaan setiap malamnya berjumlah \pm 50 -60 tutee. Hal ini berate rasio perbandingan tutor dan tutee adalah 1:4 atau setiap tutor akan membimbing kurang lebih 4 tutee.

Tabel 1. Rincian kegiatan yang dilakukan dalam kegiatan bimbingan belajar di Taman Bacaan, Bencongan.

\begin{tabular}{|c|c|c|}
\hline No. & Kegiatan & Waktu \\
\hline & $\begin{array}{c}\text { Membariskan tutee } \\
\text { dan doa pembuka }\end{array}$ & $19.30-19.40$ \\
\hline 2 & Tutoring & $19.40-20.00$ \\
\hline 3 & Latihan Soal & $20.00-20.30$ \\
\hline 4 & Doa penutup & $20.30-20.40$ \\
\hline 5 & Evaluasi tutor & $20.40-21.00$ \\
\hline
\end{tabular}

Adapun rincian kegiatan setiap bimbingan belajar berlangsung dpat dilihat pada table 1. PIC dan beberapa tutor memulai kegiatan dengan membariskan tutee dan memimpin doa berdasarkan kepercayaan masing-masing. Selanjutnya tutee akan berkumpul dengan tutor yang telah ditentukan. PIC akan membagikan meja belajar dan perlengkapan yang dibutuhkan lainnya kepada tutor dan tutee untuk mendukung kegiatan pembelajaran. Proses pendampingan belajar berlangsung selama 1 jam. Tutor akan memprioritaskan untuk membimbing tutee menyelesaikan PR dan kemudian melanjutkan untuk materi pembelajaran yang dianggap sulit bagi tutee.

Setelah kegiatan pembelajaran selesai, PIC akan kembali mengkordinir untuk menutup kegiatan pembelajaran dengan satu nyanyian yang bertujuan agar tutee tetap semangat dalam mengejar ilmu dan menggapai cita-cita dan dilanjutkan dengan doa bersama yang dipimpin oleh tutee.

Selanjutnya PIC dan tutor merapihkan tempat belajar agar dapat digunakan lagi. Kemudai PIC akan mengkordinir untuk mengadakan evaluasi kegiatan bimbingan. Hasil evaluasi dilaporkan kepada dosen penanggungjawab.

\section{HASIL DAN PEMBAHASAN}

Pelaksanaan PkM Dutasisa periode Agustus - Desember di Pos Taman Bacaan diikuti oleh 50 siswa yang terdiri dari 8 anak belum sekolah, 8 anak TK-Paud, 34 anak SD. Tingkat kehadiran 50 anak juga berada pada angka $80 \%$ berdasarkan absen. Hal ini menunjukkan antusias dari anak-anak untuk belajar bersama para tutor. Selain itu, tingkat kehadiran $92 \%$ tutor atau sebanyak 46 orang juga menunjukkan komitmen untuk hadir. Ketidakhadiran tutor disebabkan oleh sakit atau ada event yang wajib untuk dihadiri.

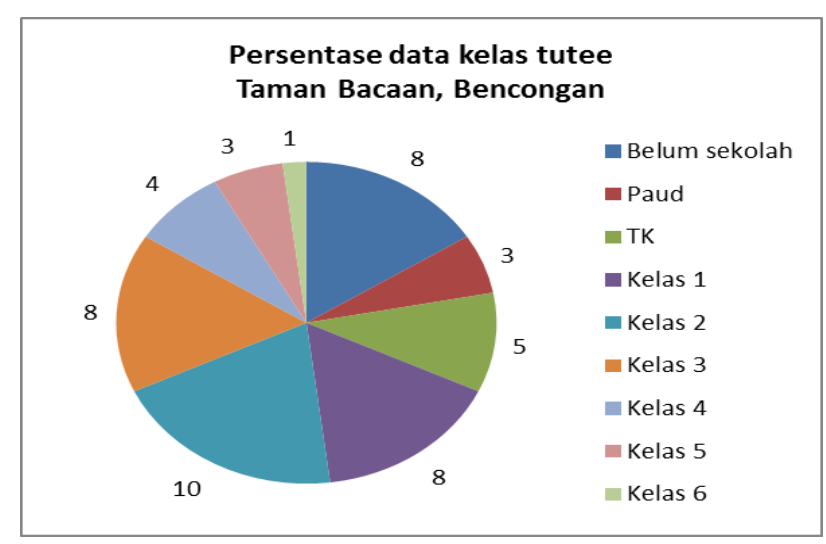

Gambar 3. Persentase data kelas tutee Taman Bacaan desa Bencongan 


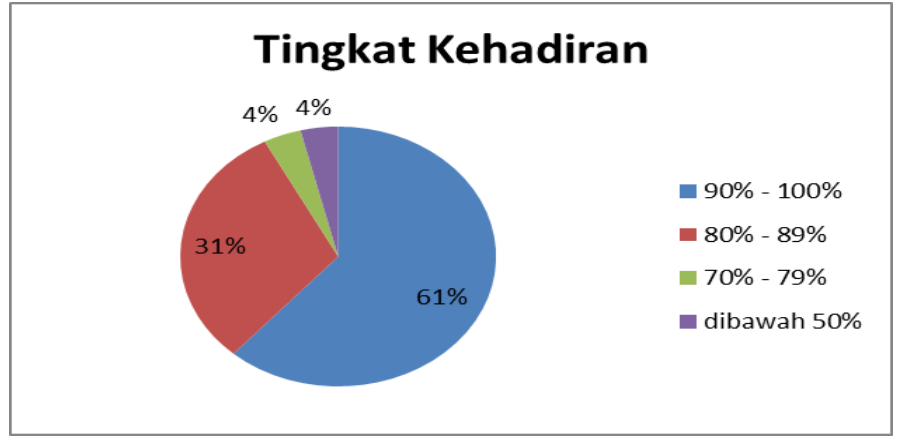

Gambar 4. Persentase kehadiran tutor Taman Bacaan, Bencongan Sumber: Hasil Pengohan Data, 2019

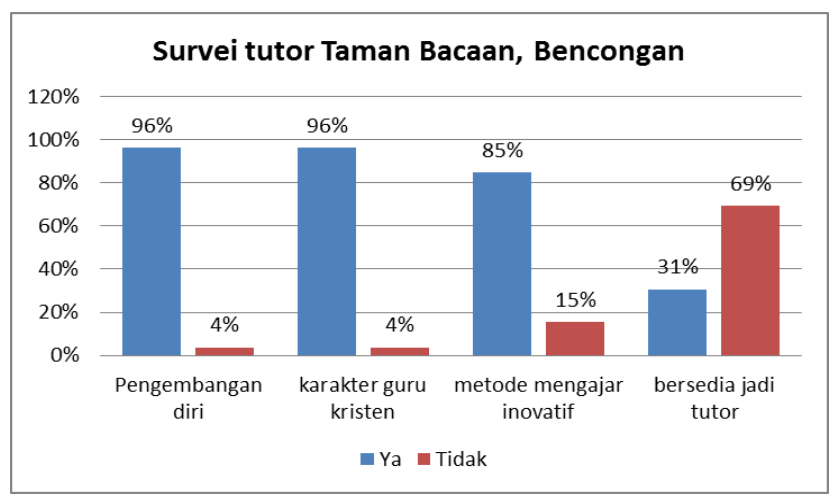

Gambar 5. Survei Tutor Taman Bacaan desa Bencongan Sumber: Hasil Pengohan Data, 2019

kegiatan pelaksanaan pegabdian kepada masyarakat melalui bimbel Taman Bacaan maka berikut ini merupakan hasil survey terhadap para tutor yang mengajar (Gambar 5).

\section{Peningkatan kemampuan akademik dan keterampilan tutee.}

Berdasarkan hasil survei yang telah dilakukan $100 \%$ tutee merasa bahwa keberadaan bimbingan belajar di Taman Bacaan membantu mereka meningkatkan kemampuan akademik bagi kelas 1-6 SD. Hal ini juga ditunjang dengan hasil raport yang menunjukkan adanya peningkatan dari $80 \%$ tutee. Sementara bagi 6 tutee yang belum sekolah, para tutor lebih menekankan aspek keterampilan motorik halus dengan kegiatan mewarnai, menggambar, menempel, serta beberapa permainan pengenalan angka dan huruf.

Peningkatan kemampuan akademik dan keterampilan tutee juga menjadi pembuktian bagi teori belajar vygotsky, khususnya mengenai scaffolding. Teori ini menggabungnya teori kognitivisme dengan sosiokulture. Ia berpendapat bahwa memberikan pendampingan kepada peserta didik oleh orang dewasa atau orang lebih memahami materi akan membantu peserta didik untuk belajar lebih banyak (Isjoni, 2013).

\section{Pengembangan diri mahasiswa sebagai tutor.}

96\% tutor mampu mengembangkan diri sebagai anggota komunitas yang signifikan dalam peningkatan mutu kehidupan masyarakat berbangsa. Daryanto dan Rahardjo (2012) mengatakan bahwa guru juga memiliki peran sebagai anggota masyarakat, baik secara langsung maupun tidak langsung. Keberadaan tutor yang mengambil bagian dalam tuga membimbing di pos dutasia tentu dapat menjadi tempat di mana mahasiswa dapat belajar untuk menempatkan diri di tengah-tengah komunitas masyarakat yang beragam.

Efek dari didikan seorang guru, tentu tidak hanya sebatas pada pelaksaan bimbingan belajar. Bahkan mungkin dapat menjadi efek domino. Seorang guru yang hanya mendidik satu anak, lalu anak ini juga bisa mendidik anak yang lain berdasarkan didikan sang guru. Hal ini, tentu dapat membuka peluang yang besar bagi guru untuk memeberikan dampak bagi komunitas. Oleh karena itu, sangat diharapkan para tutor tidak hanya sekedar

$$
\text { Pendidikan }
$$


mentransfer ilmu, tetapi juga dapat mendidik karakter tutee dengan benar.

\section{Pertumbuhan karakter mahasiswa sebagai guru Kristen.}

$96 \%$ mahasiswa juga merasa bahwa menjadi turor di taman Bacaan menjadi salah satu media yang membantu mereka untuk bertumbuh serupa Kristus. Hal tersebut karena mereka belajar untuk melihat setiap tutee sebagai imago dei. Latar belakang keluarga, lingkungan, dan keyakinan yang berbeda dengan tutee membuat tutor juga belajar menghadapi worlview yang berbeda. Mayoritas tutee datang untuk belajar menjadi pintar dan menjadi juara di sekolah masing-masing. Sementara para tutor meyakini bahwa apapun yang mereka lakukan hanya untuk kemuliaan Tuhan. Demikian halnya yang dikatakan oleh Van Brummelen (2006) bahwa pada saat seorang guru Kristen menjadi ciptaan baru dalam Kristus, maka Ia pun akan mengubah tujuan dan cara pandang kita.

\section{Penggunaan metode belajar yang inovatif.}

$85 \%$ tutor menggunakan metode pembelajaran inovatif. Metode yang paling banyak digunakan adalah permainan dan mnemonik. Metode permainan yang digunakan seperti belajar perkalian dengan kartu domino, cepat tepat, find the answer, dll. Mnemonik merupakan permainan Mnemonik merupakan salah satu teknik menghafal yang digunakan untuk mengingat informasi dalam bentuk lagu. Lirik lagu dapat diganti dengan materi pelajaran, sehingga menghapalnya pun sama seperti menyanyikan sebuah lagu. Teknik ini akan membawa informasi short term ke long term memrory sehingga anak juga mengingat infromasi tersebut lebih lama ( Blerkom , 2009, hal. 99).
Secara keseluruhan pelaksanaan $\mathrm{PkM}$ periode Agustus-Desember 2019 ini sudah berjalan dengan baik. Namun beberapa evaluasi dari pihak orang tua dan para tutor untuk agar pelaksanaan PkM ke depannya lebih baik, mengingat pelaksanaan PkM ini sudah memasuki tahun ke 7.

Evaluasi pertama mengenai efektivitas waktu. Mayoritas tutor mengeluhkan kurang efektivitas waktu. Menurut mereka waktu lebih banyak terbuang untuk menunggu tutor lainnya dan briefing sehingga waktu untuk belajar dengan tutee semakin sedikit. Berdasarkan hal tersebebut, PIC akan mengubah waktu keberangkatan lebih awal dan bersikap lebih tegas bagi tutor yang datang terlambat, serta waktu briefing hanya akan dilakukan satu kali setelah bimbingan belajar berlangsung.

Kedua, evaluasi mengenai sarana dan prasarana. Sejauh ini sarana dan prasarana semakin lengkap, khususnya perlengkapan alat tulis, meja belajar, dan tempat penyimpanan barang. Oleh karena itu, diharapkan agar penambahan perlengkapan tidak lagi difokuskan pada alat tulis saja, tetapi juga buku-buku cerita agar tutee lebih tertarik untuk membaca. Ketiga,evaluasi mengenai tempat pelaksanaan bimbingan. Pada tahun sebelumnya, bimbingan belajar dilakukan pada ruang tertutup dan lebih nyaman bagi tutor dan tutee melakukan pembelajaran. Namun, ruangan tersebut tidak dapat digunakan lagi karena sudah dialihfungsikan menjadi masjid. Sejak saat itu, taman bacaan pindah di teras rumah salah satu warga Bencongan. Kondisi ini tentu membuat konsentrasi tutee lebih dampang terpecah karena banyaknya gangguan dari luar. Selain itu, pembelajaran juga tidak dapat dilakukan jika hujan karena air hujan masuk ke teras rumah. Tindak lanjut untuk masalah ini adalah hanya memasang atap tambahan di teras untuk memanimalisir masuknya air hujan. 


\section{KESIMPULAN}

Kesimpulan dari pelaksanaan PkM ini adalah kegiatan ini berjalan dengan baik dan telah mencapai tujuan yang diharapkan. Adapun implikasi dari pelaksanaan PkM ini adalah:

1. Sebanyak $100 \%$ tuttee memiliki kemampuan akademik (pengetahuan dan keterampilan) yang telah meningkat.

2. $96 \%$ tutor mampu mengembangkan diri sebagai anggota komunitas yang signifikan dalam peningkatan mutu kehidupan masyarakat berbangsa, bernegara melalui transformasi pendidikan yang holistis.

3. 96\% Mahasiswa telah membangun karakter dan kemandirian mahasiswa sebagai seorang Kristen yang dewasa untuk menumbuhkan panggilan sebagai seorang guru Kristen.

4. $85 \%$ mahasiswa menggunakan metode mengajar yang inovatif dalam kesempatan mengajar secara langsung dengan para siswa

Adapun saran keberlanjutan berdasarkan evaluasi adalah sebagai berikut:

1. Memulai bimbingan belajar lebih awal agar waktu belajar lebih banyak

2. Menambah fasilitas buku cerita bergambar

3. Memberikan sesi bimbingan kepada orangtua mengenai pola asuh..

\section{UCAPAN TERIMAKASIH}

Ucapan terimakasih disampaikan kepada Universitas Pelita Harapan yang telah memberikan dukungan sejak tahun 2010 hingga saat ini. Kami juga mengucapkan terima kasih kepada yayasan Dutasia yang telah memfasilitasi sehingga dapat berlangsungnya kegiatan PkM ini.

\section{REFERENSI}

Brummelen, H. V. (2006). Berjalan dengan Tuhan di dalam kelas. Jakarta, Indonesia: Universitas Pelita Harapan Press.

\section{UNDANG - UNDANG REPUBLIK} INDONESIA TENTANG SISTEM PENDIDIKAN ... (n.d.). Diambil dari http://kelembagaan.ristekdikti.go.id/wpcontent/uploads/2016/08/UU_no_20_th_2003.pdf

Isjoni. (2013). Cooperative Learning: efektifitas pembelajaran kelompok. Bandung: Alfabeta

Blerkom, D. L. (2009). College study skills: Becoming a strategic learner sixth edition. USA: Wadsworth Cengage. Diambil dari https://books.google.co.id/books?id=44XFPJe4168 C\&pg=PA99\&dq=mnemonic+advantages\&hl=en\& $\underline{\mathrm{sa}=X \& \mathrm{ved}=0 \mathrm{ahUKEwiBz} 9 \mathrm{~W} 5 \mathrm{vqzfAhVPb3}}$ 